\title{
Erratum to: A new window to understanding individual differences in reward sensitivity from attentional networks
}

\author{
V. Costumero $\cdot$ A. Barrós-Loscertales • \\ J. C. Bustamante $\cdot$ P. Fuentes $\cdot$ P. Rosell-Negre $\cdot$ \\ $\mathrm{N}$. Ventura-Campos $\cdot \mathrm{C}$. Ávila
}

Published online: 14 November 2014

(c) Springer-Verlag Berlin Heidelberg 2014

\section{Erratum to: Brain Struct Funct \\ DOI 10.1007/s00429-014-0760-6}

In the original publication of the article the following errors need to be corrected regarding the references to figures and tables:

In "ICA results" section for experiment 2 , in the first sentence of the second paragraph ("The ANOVA results for this experiment (Figs. 1, 2) showed that the left sensory motor network displayed...") the figures referred should be 2 and 3 (instead of 1 and 2).

In "ICA results" section for experiment 2 , in the first sentence of the third paragraph ("The Pearson's correlations between the SR scores and IC task-related modulation appear in Table 1") the table referred should be Table 3 (instead of Table 1).

The online version of the original article can be found under doi:10.1007/s00429-014-0760-6.

V. Costumero $(\bowtie) \cdot$ A. Barrós-Loscertales .

J. C. Bustamante · P. Fuentes · P. Rosell-Negre .

N. Ventura-Campos · C. Ávila

Departamento de Psicología Básica, Clínica y Psicobiología,

Universitat Jaume I, Av. de Vicent Sos Baynat, s/n,

12071 Castelló de la Plana, Spain

e-mail: vcostume@uji.es 